\title{
Planning crowd events to achieve high participant satisfaction
}

\author{
Victoria L. Kendrick*, Roger A. Haslam and Patrick E. Waterson \\ Loughborough Design School, Loughborough University, Leicestershire, LE11 3TU, United Kingdom
}

\begin{abstract}
A case study investigation within a large UK university involving semi-structured stakeholder interviews, examined the organisation, coordination, and security within crowd events of various descriptions. Similarities in approaches and priorities emerged with crowd event organisation, primarily attention to safety requirements, in protecting crowd members, venue reputation, and legal obligations. Conversely, attention to and attitudes and beliefs surrounding user experience, crowd comfort and satisfaction, were often based on personal judgment, and appeared to be influenced by budget considerations. The findings suggest a lack of knowledge and usable evidence based guidance for planning crowd events in relation to important aspects affecting participant satisfaction.
\end{abstract}

Keywords: Crowds, Crowding, User experience, Satisfaction

\section{Introduction}

Gatherings of people (hereafter referred to as crowds) form an integral part of our everyday lives, yet research considering how the user experience of crowds can be enhanced, remains relatively underdeveloped. Substantial research surrounds crowd safety [36], and pedestrian flow modeling [27]. Meanwhile, considerations regarding crowd performance, comfort, and satisfaction received less attention [24], with a distinct lack of research concerning the user experience of crowds associated with special events (sporting and music for example) $[3,16]$.

\section{Background}

Considerable research has been carried out concerning specific factors affecting crowd experience including: satisfaction of individuals in crowds [2] $[1,25,17]$; performance of desired or necessary tasks [15]; individual personality [32, 28]; psychological reactions to a given crowd situation [33]; prior expectations and experiences $[2,30]$; gender [23, 19]; and culture $[20,21]$. However, the extent to which such information is implemented into the organisation of crowd events is unclear.

Investigation has also focused on the contribution of different crowd situations to individual experience of stress [4] and personal space preferences [7, 8, 26, 23, 13, 6, 5]. Moreover, studies have considered a range of different crowd types, including: sporting events [35, 12]; retail environments [17, 19, 31]; religious pilgrimages $[9,10]$; restaurants $[29,34,22]$; and music festivals [11]. However, there appears to be a lack of evidence based guidance for the organisation of crowd events, to achieve high participant satisfaction, with a predominance of non-evidence based literature [3].

Previous research by the authors explored the user experience of crowds through focus groups, revealing differences in factors affecting crowd satisfaction, varying with regard to age and expectations [14]. Greater differences existed between crowd users, than across crowd situations, highlighting the importance of identifying expected crowd members when planning individual events. Additionally, venue design, organisation, safety and security concerns were found to highly affect crowd satisfaction, irrespective of group differences or crowd environ-

*Corresponding author. Email: V.L.Kendrick@lboro.ac.uk +441509 228485 
ments, showing the importance of these issues when considering crowd satisfaction for all crowd events, for any crowd members. Such findings therefore formed the basis of stakeholder interview schedules, to determine whether stakeholder considerations match the priorities of crowd members.

This paper presents the findings of research undertaken with a large UK university, which routinely organises and hosts special events of various descriptions, including: music, sporting, open days, conferences and exhibitions, graduations, and participatory race events. The following crowd types were involved: ambulatory (walking); spectator (watching an activity or event); expressive (emotional release, shouting, chanting); participatory (involved in actual activities of an event); and limited movement (restricted movement) [3].

\section{Method}

Semi-structured interviews were used to investigate the organisation of crowd events, including: approaches and processes used in the planning for crowd situations; attitudes and beliefs regarding crowd satisfaction, comfort, safety, and performance; and commitment to each. Interviewees were drawn from relevant stakeholder departments across the university, using a range of methods to achieve a structured convenience sample.

A standardised interview programme was developed, with the same facilitator leading each digitally recorded interview (approximately 90 minutes). Recordings were subsequently transcribed verbatim, and imported into the qualitative software tool, NVivo (Version 9.0) to enable systematic analysis. Qualitative analysis involved: data reduction, data display, and conclusion drawing and verification [18]. Reliability was enhanced through systematic review of the data by two independent researchers.

\section{Results and Discussion}

Seventeen stakeholder interviews were conducted (nine males, eight females), across the university hierarchy (managers and coordinators; health and safety officers; security officers; and ground stewards). Stakeholders were involved in a variety of special events across the university, including: music events (students union); outdoor spectator events; open day events; conferences and exhibitions; and graduation ceremonies, for example.

Limited communication was evident between crowd event stakeholders at the university, with little sharing of knowledge and experience between events across departments. Consequently events could unknowingly occur simultaneously, or problems could be repeated during the planning of numerous events across departments.

Similarities of approaches and opinions emerged concerning crowd event organisation, primarily compliance to safety, in protecting crowd members, venue reputation, and legal obligations. Such issues emphasize the importance of compliance to health and safety standards, in order to maintain a positive reputation. These priorities are reflected in research on crowds, with a predominance of research in this area focusing on crowd safety [16]. However, well defined management systems to ensure that guidance was followed were not evident, with health, safety and security officers admitting to not always being aware of events taking place. For example, one health and safety officer said:

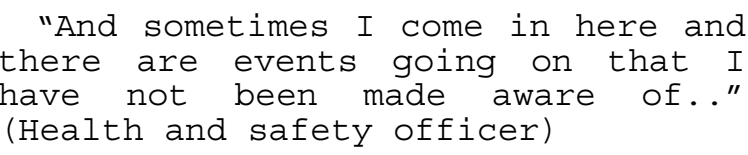

Planning and attention to crowd comfort (thermal, personal space), crowd performance (facilities, signage, logistics), and participant satisfaction, were approached less consistently; often based on "personal judgment" (Event coordinator); and influenced by budget considerations. For example one stakeholder suggested:

"Well it all comes down to money you see.. If we had enough money to have sofas for everyone, then we would.." (Spectator events coordinator)

Thus indicating that financial considerations take precedence over user comfort and satisfaction.

Provision of toilet facilities, for example, were not well linked to individual event capacity, with a number of stakeholders stating that:

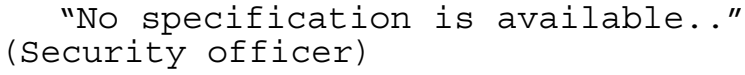

Additionally car parking was considered by some to be: 
".their (crowd members) problem rather than mine.." (Conference event orgainser)

This suggests a gap in knowledge, leading to the dismissal of facility provision, as a valid problem requiring attention.

Additionally, signage and logistics involved in directing crowd members to correct locations, appeared to be accepted as a problem inherent to crowd management, with few stakeholders concerned with overcoming shortcomings and achieving improvements. Including an event organiser:

"Well we do all that (signage).. But they still get lost.." (Open day event organiser)

Therefore highlighting limited understanding that the signage provision may be inadequate, requiring additional attention. Such findings are in line with the underdeveloped literature in this area, with a limited evidence base of knowledge, and usable guidance for planning crowd events [3, 24].

Notable differences also emerged between stakeholder groups, primarily with the planning of music events, where varying consideration to alcohol, antisocial behaviour and panic training was evident. This was also the case with anticipating target audience, and researching historical issues surrounding audience reaction to particular artists (e.g. pop groups). For example when discussing the research that goes into organising music events at the university, one stakeholder suggested:

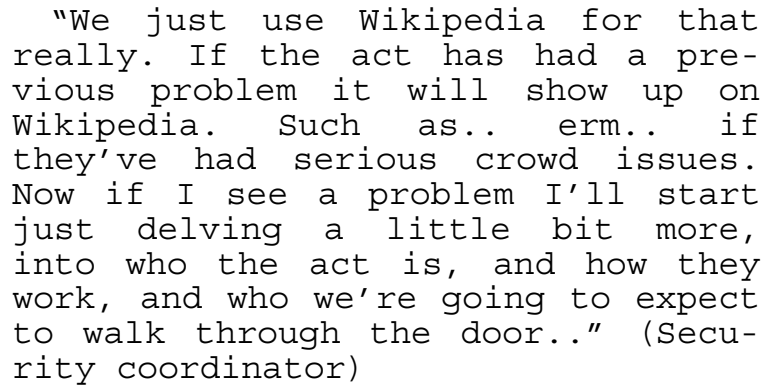

There appears to be a lack of information available to organisers involved in relatively small scale special events. Moreover, findings highlight the importance of tailoring crowd planning guidance to different crowd situations, supporting previous research [3, 16, 24].
In summary, safety was seen to be a high priority, due primarily to legal obligations, and a desire to protect venue reputation. However, comfort and satisfaction of the user often received less attention, with budget considerations cited as a key reason. Additionally, inadequate communication, and management systems were in place to ensure compliance to internal procedures, with a lack of usable guidance available to assist the organisation of special events at the university.

The findings of the study question the availability, usability, and deployment of information concerning crowd satisfaction and comfort, during the planning of crowd events. Yet achieving a positive, highquality crowd experience is desirable to their overall success, and of benefit to all stakeholders. Future research will aim to address these gaps, with the goal of contributing to improving the user experience of crowds.

\section{Reference}

[1] Altman, I. (1975). The environment and social behaviour. California: Brooks/ Cole: Montererey.

[2] Baum, A., \& Greenberg, C. I. (1975). Waiting for a crowd: The behavioral and perceptual effects of anticipated crowding. Journal of Personality and Social Psychology, 32(4), 671-679.

[3] Berlonghi, A. E. (1995). Understanding and planning for different spectator crowds. Safety Science, 18(4), 239-247.

[4] Cox, T., Houdmont, J., \& Griffiths, A. (2006). Rail passenger crowding, stress, health and safety in Britain. Transportation Research Part A: Policy and Practice, 40(3), 244-258.

[5] Evans, G. W., \& Wener, R. E. (2007). Crowding and personal space invasion on the train: Please don't make me sit in the middle. Journal of Environmental Psychology, 27(1), 90-94.

[6] Gérin-Lajoie, M., Richards, C. L., \& McFadyen, B. J. (2005). The negotiation of stationary and moving obstructions during walking: Anticipatory locomotor adaptations and preservation of personal space. Motor Control, 9(3), 242.

[7] Hasse, R. F., \& Markey, M. J. (1973). A methodological note on the study of personal space. Journal of Consulting and Clinical Psychology, 40(1), 122-125.

[8] Hayduk, L. A. (1983). Personal space: Where we now stand. Psychological Bulletin, 94(2), 293-335.

[9] Hughes, R. L. (2002). A continuum theory for the flow of pedestrians. Transportation Research Part B: Methodological, 36(6), 507-535.

[10]Hughes, R. L. (2003). The flow of human crowds. Annual Review of Fluid Mechanics, 35(1), 169-182.

[11]Janchar, T., Samaddar, C., \& Milzman, D. (2000). The mosh pit experience: Emergency medical care for concert injuries. The American Journal of Emergency Medicine, 18(1), 62-63.

[12] Johnson, C. W. (2008). Using evacuation simulations for contingency planning to enhance the security and safety of the 2012 olympic venues. Safety Science, 46(2), 302-322.

[13]Kaya, N., \& Erkip, F. (1999). Invasion of personal space under the condition of short-term crowding: A case study of 
an automatic teller machine. Journal of Environmental Psychology, 19(2), 183-189.

[14] Kendrick and Haslam, 2010. The user experience of crowds a human factors challenge. Human Factors and Ergonomics Society 54th Annual Meeting, San Francisco.

[15]Klein, K., \& Harris, B. (1979). Disruptive effects of disconfirmed expectancies about crowding. Journal of Personality and Social Psychology, 37(5), 769-777.

[16]Lee, R. S. C., \& Hughes, R. L. (2007). Minimisation of the risk of trampling in a crowd. Mathematics and Computers in Simulation, 74(1), 29-37.

[17] Machleit, K. A., Eroglu, S. A., \& Mantel, S. P. (2000). Perceived retail crowding and shopping satisfaction: What modifies this relationship? Journal of Consumer Psychology, 9(1), 29-42.

[18]Miles, M. B. \& Huberman, A. M. (1994). Qualitative Data Analysis; An Expanded Sourcebook (2nd ed.). London: Sage Publications.

[19] Ozdemir, A. (2008). Shopping malls: Measuring interpersonal distance under changing conditions and across cultures. Field Methods, 20(3), 226-248.

[20]Pons, F., Laroche, M., \& Mourali, M. (2006). Consumer Reactions to Crowded Retail Settings: Cross-Cultural Differences between North America and the Middle East. Psychology \& Marketing, 23(7): 555-572.

[21] Pons, F., \& Laroche, M. (2007). Cross-cultural differences in crowd assessment. Journal of Business Research, 60(3), 269276.

[22] Robson, S. K. A. (2008). Scenes from a restaurant: Privacy regulation in stressful situations. Journal of Environmental Psychology, 28(4), 373-378.

[23]Rüstemli, A. (1992). Crowding effects of density and interpersonal distance. Journal of Social Psychology, 132(1), 51-58.

[24]Ryan, C., Shih Shuo, Y., \& Huan, T. (2010). Theme parks and a structural equation model of determinants of visitor satisfaction - Janfusan Fancyworld, Taiwan. Journal of Vacation Marketing, 16(3), 185-199.
[25] Schmidt, D. E., \& Keating, J. P. (1979). Human crowding and personal control: An integration of the research. Psychological Bulletin, 86(4), 680-700.

[26] Sinha, S. P., \& Sinha, S. P. (1991). Personal space and density as factors in task performance and feeling of crowding. Journal of Social Psychology, 131(6), 831-837.

[27] Smith, A., James, C., Jones, R., Langston, P., Lester, E., \& Drury, J. (2009). Modelling contra-flow in crowd dynamics DEM simulation. Safety Science, 47(3), 395-404.

[28] Spacapan, S., \& Cohen, S. (1983). Effects and aftereffects of stressor expectations. Journal of Personality and Social Psychology, 45(6), 1243-1254.

[29] Tse, A. C. B., Sin, L., \& Yim, F. H. K. (2002). How a crowded restaurant affects consumers' attribution behavior. International Journal of Hospitality Management, 21(4), 449454.

[30] Webb, W. M., \& Worchel, S. (1993). Prior experience and expectation in the context of crowding. Journal of Personality and Social Psychology, 65(3), 512-521.

[31] Whiting, A., \& Nakos, G. (2008). Functional density and its impact on retail satisfaction in cross-cultural contexts: can crowded stores be a good thing for retailers. International Business: Research Teaching and Practice, 2(1).

[32] Worchel, S., \& Teddie, C. (1976). The experience of crowding: A two-factor theory. Journal of Personality and Social Psychology, 34(1), 30-40.

[33] Worchel, S., \& Yohai, S. M. L. (1979). The role of attribution in the experience of crowding. Journal of Experimental Social Psychology, 15(1), 91-104.

[34] Yildirim, K., \& Akalin-Baskaya, A. (2007). Perceived crowding in a café/ restaurant with different seating densities. Building and Environment, 42(9), 3410-3417.

[35]Zhang, Q., Liu, M., Wu, C., \& Zhao, G. (2007). A strandedcrowd model (SCM) for performance-based design of stadium egress. Building and Environment, 42(7), 2630-2636.

[36]Zhen, W., Mao, L., \& Yuan, Z. (2008). Analysis of trample disaster and a case study - Mihong bridge fatality in China in 2004. Safety Science, 46(8), 1255-1270. 